\title{
Rhabdomyolysis after transplantation: case report after allogeneic hematopoietic transplantation and review of literature
}

\begin{abstract}
We describe a case of flaccid paraparesis, intervening during treatment with simvastatin cyclosporine and low dose posaconazole, in a patient previously having undergone allogeneic hematopoietic transplantation. Final diagnosis was rhabdomyolysis related to statin. This is the first case reporting posaconazole as an agent favoring rhabdomyolysis when administered together with simvastatin and cyclosporine. In this patient, a low Vitamin D level may also have contributed to establishing rhabdomyolysis. Literature on rhabdomyolysis in transplanted patients is reviewed. Therapeutic choices in transplanted patients needing concomitant therapy with azole and statin are discussed.
\end{abstract}

Keywords: rhabdomyolysis, statin, hematopoietic stem cell transplantation, myopathy

\author{
Volume 2 Issue I - 2017 \\ Leotta S, Pirosa C, Cupri A, Martino E, \\ Spadaro A, Milone Giuseppe \\ Department of Haematology, Azienda Policlinico Vittorio \\ Emanuele Catania, Italy
}

Correspondence: Giuseppe Milone, BMT Unit, Department of Haematology, Azienda Policlinico Vittorio Emanuele Catania, Italy, Tel 0039095.7436|58, Fax 0039095.74359|3,

Email Giuseppe.milone@gmail.com

Received: November 28, 2016 | Published: January 25, 2017
Abbreviations: VDR, vitamin d receptors; MINE, mesna, ifosfamide, mitoxantrone, and etoposide; PBPC, peripheral blood progenitor cell apheresis; GVHD, graft versus host disease; CSA, cyclosporine; CYP3A4, cytochrome p450 3a4 enzyme; PBPC, peripheral blood progenitor cell apheresis

\section{Introduction}

Rhabdomyolysis is a rare and potentially fatal condition. ${ }^{1}$ After allogeneic hematopoietic stem cell transplantation, rhabdomyolysis has been reported in association with bacterial ${ }^{2}$ and fungal ${ }^{3}$ infections, and has also occurred as a complication of sulfamethoxazole/ trimethoprim $^{4}$ and statin $^{5,6}$ administration. The frequency of rhabdomyolysis increases during statin therapy concomitant with cyclosporine. ${ }^{5,7}$ The risk of this complication during statin therapy can increase further with the concomitant use of third agents such as macrolides and some azoles, such ketoconazole and itraconazole. ${ }^{8-11}$

We here describe a patient who presented with flaccid paraparesis due to rhabdomyolysis, 2 months after having undergone allogeneic hematopoietic stem cell transplantation and during combined therapy with cyclosporine, statin and low dose posaconazole. This is the first case reporting posaconazole as an agent contributing to rhabdomyolysis together with simvastatin and cyclosporin.

\section{Case report}

The patient was diagnosed with non-Hodgkin lymphoma, mantle cell type, at the age of 51 years, on November 2007. He had stage IV-B by the Ann Arbor lymphoma staging system. He received for as firstline treatment R-CHOP (rituximab, vincristine cyclophosphamide, adriamicin and prednisolone), followed by HYPER-C-VAD (cyclophosphamide, vincristine, Adriamycin, and dexamethasone alternated with high-dose cytarabine and methotrexate) and showed a complete response, defined as complete disappearance of all lymphoma lesions that were present at diagnosis. The response was consolidated in February 2009 with high-dose BEAM (Bis-chloroNitrosurea, etoposide, cytarabine and melphalan) chemotherapy and autologous peripheral blood stem cell transplantation. The patient relapsed 65 months later, on August 2014. The patient underwent chemotherapy consisting of 4 cycles of MINE (mesna, ifosfamide, mitoxantrone, and etoposide) followed by 2 cycles of ESHAP (etoposide, methylprednisolone, high-dose cytarabine, and cisplatin), and achieved a second complete remission. On October $26^{\text {th }}, 2015$, at the age of 60 years, while in his second complete remission, the patient received an allogeneic hematopoietic stem cell transplant from an 8/8 HLA-matched unrelated donor. The stem cell source was obtained by G-CSF mobilization and Peripheral Blood Progenitor Cell Apheresis (PBPC). A reduced-intensity conditioning regimen based on thiotepa, cyclophosphamide, and fludarabine was used, with antithymocyte globulin administered at a total dose of $5 \mathrm{mg} / \mathrm{Kg}$. Graft versus Host Disease (GVHD) prophylaxis consisted of cyclosporine (CSA) $3 \mathrm{mg} / \mathrm{Kg}$ iv and short-term methotrexate administered iv for 4 doses, on days $+1,+3,+6,+11$.

On day +5 , idiopathic pneumonia syndrome was diagnosed, and because of this lung toxicity, he was started on corticosteroids at $1.5 \mathrm{mg} / \mathrm{kg}$ for 1 week, with rapid tapering. Neutrophil engraftment was achieved at day +11 . On day +30 , the patient was discharged on CSA at dose of $3.5 \mathrm{mg} / \mathrm{Kg} /$ day po and prednisolone $0.5 \mathrm{mg} /$ $\mathrm{kg}$ po, posaconazole $200 \mathrm{mg} \mathrm{q} 12 \mathrm{~h}$ po was also prescribed, as anti mould infection prophylaxis. Trough levels of CSA were assayed in whole blood weekly from the day of transplant to day +100 by chemiluminescent microparticle immunoassay (Abbot- DE), (therapeutic range: $200-400 \mathrm{ng} / \mathrm{ml}$ ) and dosage of CSA modified accordingly to blood level. On day +45 , simvastatin $20 \mathrm{mg} /$ day po was added to the treatment regimen for hypertriglyceridemia $(279 \mathrm{mg} /$ $\mathrm{dL})$ and hypercholesterolemia $(236 \mathrm{mg} / \mathrm{dL})$ revealed by routine monitoring. At start of simvastatin treatment no neurological or myopathy symptoms were present; CSA level was $279 \mathrm{ng} / \mathrm{ml}$ (day +43 ), however, after 1 week, an increase of CSA level was noted (478ng/ml), no signs of liver, renal or neurological dysfunction were present, and a $30 \%$ decrease of cyclosporine dose was instituted, this promptly resulted in a CSA plasma level within therapeutic range. 
After nine days of simvastatin treatment, on day +54 after transplantation, the patient complained of difficulty in walking. There was no fever, no headache, no abnormality of consciousness, neck was supple and no focal neurological defects were present, a bilateral hypo-asthenia in lower limbs was noticed, however, the patellar tendon reflex and sensitivity to tactile and pain stimuli were bilaterally intact. The patient was thought to suffer a corticosteroid associated myopathy and therefore prednisolone dose was reduced to $0.25 \mathrm{mg} / \mathrm{kg}$. However, 7 days later, on day +61 , the hypo-asthenia had worsened and he was found unable to walk and to stand from the supine position. Again there was no sign of infection, no headache, no abnormality of consciousness, neck was supple and no focal neurological deficits were present, patellar tendon reflexes and sensitivity to tactile and pain stimuli in right and left legs and foots were found intact. On the same day he was admitted into hospital with clinical suspicious of rhabdomyolysis and a plasma CPK assay was immediately performed. At that time blood CSA level was found to be within therapeutic range $(345 \mathrm{ng} / \mathrm{ml})$.

Laboratory findings on day +61 included the following: AST 2,617 $\mathrm{IU} / \mathrm{ml}$, normal values (nv) 0-50, ALT $925 \mathrm{IU} / \mathrm{ml}$ (nv: 0-50), CPK 111,460 U/mL (nv: 0-171), myoglobinuria, and proteinuria. Bilirubin, BUN, alkaline phosphatase, thyroid hormones and creatinine levels were all within normal ranges. The findings from brain computed tomography and nuclear magnetic resonance imaging, performed at day +62 , were unremarkable. In blood drawn on day +61 , patient's vitamin D level was found to be markedly reduced: $10 \mathrm{mcg} / \mathrm{ml}$ (nv: $>20 \mathrm{mcg} / \mathrm{ml}$ ).

Simvastatin and posaconazole were immediately discontinued $($ day +61$)$; and the patient received intravenous hydration $\left(3 \mathrm{~L} / \mathrm{m}^{2}\right)$ and urine alkalinization by iv sodium bicarbonate. The patient's strength improved rapidly; and his CPK, ALT, and AST levels dropped over a few days. From day +70 he received a weekly Vitamin D supplementation (2000 IU, po). The patient was discharged two weeks later, on day +75 . At the time of writing, he was +335 days after transplantation, with a Karnofsky score ${ }^{12}$ of $80 \%$ and no sign of underlying disease. He was still receiving cyclosporine and a lowdose steroid for chronic GVHD involving his skin and mouth.

\section{Discussion}

Hypercholesterolemia and hypertriglyceridemia develop in 40\%$70 \%$ of patients after transplantation of solid organs or hematopoietic stem cells ${ }^{13-15}$ and contribute to the high frequency of cardiovascular disease in transplant patients. ${ }^{16,17} \mathrm{In}$ addition to the main risk factors seen for the general population, such as obesity, diabetes, hypogonadism, hypothyroidism and genetic factors, transplant patients have specific predisposing factors for hyperlipidemia, such as treatment with corticosteroids or immunosuppressive agents (cyclosporine, sirolimus, and to a lesser extent, tacrolimus). Acute and chronic GVHD are also important with regard to hyperlipidemia, independently of any treatment administered..$^{13}$

Statins are effective for controlling the hypercholesterolemia and hypertriglyceridemia of patients who have received an allogeneic hematopoietic stem cell transplant ${ }^{13-17}$ or solid organ transplant. ${ }^{18,19}$ However, statins are pleiotropic compounds provided with antiinflammatory, immunomodulatory, and antithrombotic effects. Based on such effects, statins have also been proposed after allogeneic transplantation as prophylaxis for reducing the risk of acute and chronic GVHD. ${ }^{20,21}$
Myopathy is a known adverse event associated with statin treatment. Statin-associated myopathy is defined by muscle symptoms and in elevated CPK $>10$ above normal value. It occurs only rarely in the general population $(0.1 \%){ }^{22}$ The more severe form of muscle damage, rhabdomyolysis, is defined as an elevation of CPK $>50$ fold that of normal value, myoglobinemia, myoglobinuria and myoglobin induced renal failure. Rhabdomyolysis during statin treatment has an incidence $<0.0001 \%{ }^{22}$

After treatments using cyclosporine and statins, a total of 27 cases of rhabdomyolysis have been reported in the literature. Twenty cases of rhabdomyolysis have been reported after solid organ transplantation, ${ }^{23-42} 2$ cases after allogeneic hematopoietic stem cell transplantation ${ }^{5,6}$ while 5 cases of rhabdomyolysis occurred in patients assuming cyclosporine for other clinical reasons. ${ }^{7,43-46}$ In heart transplant recipients treated with statins, frequency of myopathy was estimated between $10 \%$ and $20 \%,{ }^{47}$ while in a retrospective study of patients who underwent marrow transplant and were treated with statins, myopathy was found in $1 \% .{ }^{13}$ Since in transplanted heart recipients, as in hematopoietic transplant recipients, the frequency of myopathy after statin treatment is increased with respect to that found in the general population, an increased risk of rhabdomyolysis could be expected in transplanted patients. Indeed, in a retrospective study that examined the course of 20,366 patients who received renal transplantation, there were 62 individual cases of rhabdomyolysis with a cumulative incidence of $0.3 \%{ }^{48}$ More data regarding the risk of statin-related rhabdomyolysis after various types of transplantation are required.

The increased incidence of myopathy in transplanted patients who are treated with cyclosporine and statins is thought to result from the fact that cyclosporine and most statins are metabolized by the cytochrome P450 3A4 enzyme (CYP3A4). Such agents, administered together, compete for the same metabolic pathway, leading to increased plasma levels of both drugs. ${ }^{49}$ Inhibition of organic anion transporting polypeptide 1B1 (OATP1B1) by cyclosporine may also contribute to such pharmacological interactions, and cyclosporine inhibition of OATP1B1 can, in fact, lead to an increase in the area under the concentration-time curve (AUC) of statins. ${ }^{8}$ The incidence of rhabdomyolysis is also increased by the concomitant use of statins metabolized by CYP3A4 together with agents that inhibit CYP3A4, such as azoles, verapamil, diltiazem, amiodarone, protease inhibitors, fibrate, tricyclic antidepressants, midazolam, tamoxifen and macrolides. ${ }^{8,22}$

Accordingly, in 9 out of the 22 case reports of myopathy occurring as an adverse effect of statins after transplantation, , $5,623-42$ the patients receiving a statin and cyclosporine were also treated concomitantly with agents inhibiting CYP3A4, as follows: risperidone (1 case), verapamil (1 case), macrolides (1 case), itraconazole (1 case), clopidogrel (1 case), fibrate ( 1 case), fusidic acid ( 1 case), gemfibrozil ( 1 case) and multiple agents ( 1 case). In the other 13 cases, rhabdomyolysis was associated with the concomitant use only of cyclosporine and statins. The role that inhibitors of CYP3A4 play in statin-associated myopathy is well established, and the use of azoles together with statins is discouraged, independent of any use of cyclosporine.$^{50}$ Rhabdomyolysis occurred in our patient while he was taking simvastatin together with cyclosporine and posaconazole. We assume that posaconazole might have contributed, even though posaconazole has the lowest inhibitory activity of any azole against CYP3 $44^{51,52}$ and although posaconazole was administered at low 
dosage. Our case confirms that the use of simvastatin in a patient taking cyclosporine and posaconazole should be avoided. ${ }^{53}$ However, posaconazole is widely used after allogeneic transplantation, because it is considered to be the first-line drug for antifungal prophylaxis for patients with GVHD who are being treated with cyclosporine and corticosteroids. ${ }^{54}$ Indeed, the possibility to avoid a concomitant treatment with simvastatin and posaconazole is quite different in general population versus in transplanted patients.

In fact, in general population, a posaconazole treatment is commonly a short length situation and in this case the simvastatin can be easily withdrawn. On the contrary, in transplanted patients, posaconazole is frequently administered as anti-mould prophylaxis in patients treated by corticosteroids, and this treatment lasts usually for some months, therefore in this clinical situation avoidance of lipid lowering agent is not easily done. Furthermore, the patient needing posaconazole prophylactic treatment typically is the one affected by chronic GvHD and this type of patients has a great chance of developing hyperlipidemia and, therefore, is often in need of statin therapy.

Choosing an antilipidemic agent for patients treated with cyclosporine and possibly with an azole is problematic. Pravastatin, rovusastatin, and pitavastatin are excreted unmodified and are not metabolized by CYP3A4. ${ }^{8,22}$ However, during treatment with cyclosporine, the pravastatin level has shown a 4 - to 23 -fold increase ${ }^{55}$ because of the inhibitory activity of cyclosporine against the carriermediated biliary excretion of statins

The metabolism of fluvastatin is independent of CYP3A4; it is metabolized primarily by CYP2C9. It is also unaffected by OATP1B1, and thus AUC of fluvastatin is not affected by cyclosporine. Therefore, fluvastatin may be a safer choice for patients treated with cyclosporine who need a statin. ${ }^{56}$ Other agents that may be safe to use for hyperlipidemia in cases requiring concomitant cyclosporine treatment are fibrate and niacin..$^{53}$ In addition, if a patient on cyclosporine is prescribed simvastatin, its dosage should be reduced. ${ }^{57}$

Since hyperlipidemia frequently occurs in patients after allogeneic hematopoietic stem cell transplantation, studies comparing the adverse effects of different antilipidemic agents in patients taking cyclosporine seem warranted. These studies might also be useful in identifying the factors predictive for rhabdomyolysis. A low vitamin D level may be involved. A reduced vitamin D level is frequently found after hematopoietic stem cell transplantation; and a low level, which was seen in our patient, seems to be important in statinassociated rhabdomyolysis. ${ }^{58}$ In fact, vitamin D is thought to exert a direct trophic effect on skeletal muscle cells and vitamin D receptors (VDR) have been demonstrated on skeletal muscle cells. ${ }^{59}$ In adults with vitamin D deficiency, atrophy of muscle fiber type II has been found. ${ }^{60}$

Vitamin D exerts also an indirect beneficial effect on skeletal muscle through enhanced absorption of calcium and phosphate. ${ }^{61}$ Correcting the vitamin $\mathrm{D}$ levels in patients receiving a statin and cyclosporine is therefore indicated. Finally, knowledge of the pharmacological interactions between cyclosporine, statins, and azoles is of the utmost importance for the prevention and early recognition of rhabdomyolysis in the transplantation setting.

\section{Acknowledgements}

None.

\section{Conflict of interest}

The author declares no conflict of interest.

\section{References}

1. Melli G, Chaudhry V, Cornblath DR. Rhabdomyolysis: an evaluation of 475 hospitalized patients. Medicine (Baltimore). 2005;84(6):377-385.

2. Martino R, Nomdedéu J, Sureda A, et al. Acute rhabdomyolysis complicating viridans streptococcal shock syndrome. Acta Haematol. 1994;92(3):140-141

3. Kakiuchi S, Yakushijin K, Yamamoto K, et al. Rhabdomyolysis caused by candida parapsilosis in a patient with acute myeloid leukemia after bone marrow transplantation. Intern Med. 2015;54(16):2057-2060.

4. Kiel PJ, Dickmeyer N, Schwartz JE. Trimethoprim-sulfamethoxazoleinduced rhabdomyolysis in an allogeneic stem cell transplant patient. Transpl Infect Dis. 2010;12(5):451-454.

5. Tong J, Laport G, Lowsky R. Rhabdomyolysis after concomitant use of cyclosporine and simvastatin in a patient transplanted for multiple mieloma. Bone Marrow Transplant. 2005;36(8):739-740.

6. Vives S, Batlle M, Montané E, et al. Rhabdomyolysis and renal failure secondary to interaction between simvastatin, ciclosporin A and risperidone in an allogeneic stem cell transplantation patient. Med Clin (Barc). 2008;131(17):676.

7. Hong R, Sequeira W. Rhabdomyolysis in a patient taking simvastatin after addition of cyclosporine therapy. $J$ Clin Rheumatol. 2000;6(6):324-327.

8. Neuvonen PJ, Niemi M, Backman JT. Drug interaction with lipid lowering drugs: mechanisms and clinical relevance. Clin Pharmacol Ther. 2006;80(6):565-581.

9. Barba P, Piñana JL, Valcárcel D, et al. Early and late neurological complications after reduced-intensity conditioning allogeneic stem cell transplantation. Biol Blood Marrow Transplant. 2009;15(11):14391446.

10. Rodriguez V, Kuehnle I, Heslop HE, et al. Guillain-Barré syndrome after allogeneic hematopoietic stem cell transplantation. Bone Marrow Transplant. 2002;29(6):515-517.

11. Wong R, Beguelin GZ, De Lima M, et al. Tacrolimus-associated posterior reversible encephalopathy syndrome after allogeneic haematopoietic stem cell transplantation. Br J Haematol. 2003;122(1):128-134.

12. Verger E, Salamero M, Conill C. Can Karnofsky performance status be transformed to the eastern cooperative oncology group scoring scale and vice-versa. Eur J Cancer. 1992;28A(8-9):1328-1330.

13. Blaser BW, Kim HT, Alyea EP, et al. Hyperlipidemia and statin use after allogeneic hematopoietic stem cell transplantation. Biol Blood Marrow Transplant. 2012;18(4):575-583.

14. Kagoya Y, Seo S, Nannya Y, et al. Hyperlipidemia after allogeneic stem cell transplantation: prevalence, risk factors, and impact on prognosis Clin Transplant. 2012;26(2):E168-E175.

15. Griffith ML, Savani BN, Boord JB. Dyslipidemia after allogeneic hematopoietic stem cell transplantation: evaluation and management. Blood. 2010;116(8):1197-1204.

16. Baker KS, Ness KK, Steinberger J, et al. Diabetes, hypertension and cardiovascular events in survivors of hematopoietic transplantation:a report from the bone marrow transplantation survivor study. Blood. 2007;109(4):1765-1772.

17. Tichelli A, Bucher C, Rovo A, et al. Premature cardiovascular disease after allogeneic hematopoietic stem-cell transplantation. Blood. 2007;110(9):3463-3471. 
18. Wenke K, Meiser B, Thiery J, et al. Simvastatin reduces graft vessel disease and mortality after heart transplantation: a four-year randomized trial. Circulation. 1997;96(5):1398-1402.

19. Holdaas H, Fellström B, Cole E, et al. Long-term cardiac outcomes in renal transplant recipients receiving fluvastatin: the ALERT extension study. Am J Transplant. 2005;5(12):2929-2936.

20. Hamadani M, Awan FT, Devine SM. The impact of HMG-CoA reductase inhibition on the incidence and severity of graft-versus-host disease in patients with acute leukemia undergoing allogeneic transplantation. Blood. 2008;111(7):3901-3902.

21. Rotta M, Storer BE, Storb R, et al. Impact of recipient statin treatment on graft-versus-host disease after allogeneic hematopoietic cell transplantation. Biol Blood Marrow Transplant. 2010;16(10):1463-1466.

22. Bellosta S, Paoletti R, Corsini A. Safety of statins: focus on clinical pharmacokinetics and drug interactions. Circulation. 2004;109(23 Suppl 1):III50-III57.

23. Weise WJ, Possidente CJ. Fatal rhabdomyolysis associated with simvastatin in a renal transplant patient. Am J Med. 2000;108(4):351-352.

24. Alejandro DS, Petersen J. Myoglobinuric acute renal failure in a cardiac transplant patient taking lovastatin and cyclosporine. J Am Soc Nephrol. 1994;5(2):153-160.

25. Dos Santos AG, Guardia AC, Pereira TS, et al. Rhabdomyolysis as a clinical manifestation of association with ciprofibrate, sirolimus, cyclosporine, and pegylated interferon $-\alpha$ in liver-transplanted patients: a case report and literature review. Transplant Proc. 2014;46(6):18871888 .

26. Kusus M, Stapleton DD, Lertora JJ, et al. Rhabdomyolysis and acute renal failure in a cardiac transplant recipient due to multiple drug interactions. Am J Med Sci. 2000;320(6):394-397.

27. Vlahakos DV, Manginas A, Chilidou D, et al. Itraconazole-induced rhabdomyolysis and acute renal failure in a heart transplant recipient treated with simvastatin and cyclosporine. Transplantation. 2002;73(12):1962-1964

28. Scarfia RV, Clementi A, Granata A. Rhabdomyolysis and acute kidney injury secondary to interaction between simvastatin and cyclosporine. Ren Fail. 2013;35(7):1056-1057.

29. Burton JR, Burton I, Pearson GJ. Clopidogrel-precipitated rhabdomyolysis in a stable heart transplant patient. Ann Pharmacother. 2007;41(1):133-137

30. Valero R, Rodrigo E, Zubimendi JA, et al. Rhabdomyolysis secondary to the interaction of statins with macrolides in a renal transplant patient. Nefrologia. 2004;24(4):382-383.

31. Chiffoleau A, Trochu JN, Veyrac G, et al. Rhabdomyolysis in cardiac transplant recipient due to verapamil interaction with simvastatin and cyclosporin treatment. Therapie. 2003;58(2):168-170.

32. Maxa JL, Melton LB, Ogu CC, et al. Rhabdomyolysis after concomitant use of cyclosporine, simvastatin, gemfibrozil, and itraconazole. Ann Pharmacother. 2002;36(5):820-823.

33. Rodríguez JA, Crespo Leiro MG, Paniagua MJ, et al. Rhabdomyolysis in transplant patients on $\mathrm{HMG}-\mathrm{CoA}$ reductase inhibitors and cyclosporine. Transplant Proc. 1999;31(6):2522-2523.

34. East C, Alivizatos PA, Grundy SM, et al. Rhabdomyolysis in patients receiving lovastatin after cardiac transplantation. $N$ Engl J Med. 1988;318(1):47-48.

35. Blaison G, Weber JC, Sachs D, et al. Rhabdomyolysis caused by simvastatinin a patient following heart transplantation and cyclosporine therapy. Rev Med Interne. 1992;13(1):61-63.
36. Corpier CL, Jones PH, Suki WN, et al. Rhabdomyolysis and renal injury with lovastatin use. Report of two cases in cardiac transplant recipients. JAMA. 1988;260(2):239-241.

37. De Alava E, Sola JJ, Lozano MD, et al. Rhabdomyolysis and acute renal failure in a heart transplant recipient treated with hypolipemiants. Nephron. 1994;66(2):242-243.

38. Rifkin SI. Multiple drug interactions in a renal transplant patient leading to simvastatin-induced rhabdomyolysis: a case report. Medscape $J$ Med. 2008;10(11):264.

39. Chagnac A, Wisnovitz M, Zevin D, et al. Cyclosporin-associated rhabdomyolysis and anterior compartment syndrome in a renal transplant recipient. Clin Nephrol. 1993;39(6):351-352.

40. Kotanko P, Kirisits W, Skrabal F. Rhabdomyolysis and acute renal graft impairment in a patient treated with simvastatin, tacrolimus, and fusidic acid. Nephron. 2002;90(2):234-235

41. Mora C, Rodríguez ML, Navarro JF. Cerivastatin-induced rhabdomyolysis in a renal transplant on cyclosporin. Transplantation. 2001;72(3):551.

42. Gumprecht J, Zychma M, Grzeszczak W, et al. Simvastatin-induced rhabdomyolysis in a CsA-treated renal transplant recipient. $\mathrm{Med} \mathrm{Sci}$ Monit. 2003;9(9):CS89-CS91.

43. Lasocki A, Vote B, Fassett R, et al. Simvastatin-induced rhabdomyolysis following cyclosporine treatment for uveitis. Ocul Immunol Inflamm. 2007;15(4):345-346.

44. Maltz HC, Balog DL, Cheigh JS. Rhabdomyolysis associated with concomitant use of atorvastatin and cyclosporine. Ann Pharmacother. 1999;33(11):1176-1179.

45. Yang WH, Zeng ZS, Ren XW, et al. Simvastatin-induced myopathy with concomitant use of cyclosporine:case report. Int J Clin Pharmacol Ther. 2011;49(12):772-777.

46. Hermida Lazcano I, Revillo Pinilla P, Nerin Sánchez C, et al. Rhabdomyolysis in a atient treated with lovastatin and cyclosporine. An Med Interna. 1997;14(9):488.

47. Marzoa Rivas R, Crespo Leiro MG, Paniagua Marin MJ, et al. Safety of statins when response is carefully monitored: a study of 336 heart recipients. Transplant Proc. 2005;37(9):4071-4073.

48. Hurst FP, Neff RT, Jindal RM, et al. Incidence, predictors and associated outcomes of rhabdomyolysis after kidney transplantation. Nephrol Dial Transplant. 2009;24(12):3861-3866.

49. Watkins PB. Role of cytochromes P450 in drugs metabolism and hepatotoxicity. Sem Liver Disease. 1990;10(4):235-250.

50. Lees RS, Lees AM. Rhabdomyolysis from the coadministration of lovastatin and the antifungal agent itraconazole. $N$ Engl $J$ Med. 1995;333(10):664-665

51. Krishna G, Moton A, Ma L, et al. Effects of oral posaconazole on the pharmacokinetic properties of oral and intravenous midazolam:a phase I, randomized, open-label, crossover study in healthy volunteers. Clin Ther. 2009;31(2):286-298.

52. Niwa T, Imagawa Y, Yamazaki H. Drug interactions between nine antifungal agents and drugs metabolized by human cytochromes P450. Curr Drug Metab. 2014;15(7):651-679.

53. Marini BL, Choi SW, Byersdorfer CA, et al. Treatment of dyslipidemia in allogeneic hematopoietic stem cell transplant patients. Biol Blood Marrow Transplant. 2015;21(5):809-820.

54. Pagano L, Caira M. The role of primary antifungal prophylaxis in patients with haematological malignancies. Clin Microbiol Infect. 2014; 20 Suppl 6:19-26. 
55. Corsini A, Bellosta S, Baetta R, et al. New insights into the pharmacodynamic and pharmacokinetic properties of statins. Pharmacol Ther. 1999;84(3):413-428.

56. Sadoni S, Kaczmarek I, Delgado O, et al. as co-medication in heart transplant recipients with elevated creatine-kinase. Transplant Proc. 2007;39(2):558-559.

57. Bilchick KC, Henrikson CA, Skojec D, et al. Treatment of hyperlipidemia in cardiac transplant recipients. Am Heart J. 2004;148(2):200 210

58. Khayznikov M, Hemachrandra K, Pandit R, et al. Statin intolerance because of myalgia, myositis, myopathy, or myonecrosis can in most cases be safely resolved by vitamin D supplementation. $N$ Am J Med Sci. 2015;7(3):86-93.
59. Bischoff HA, Borches M, Gudat F, et al. In situ detection of 1,25 dihydroxyvitamin D3 receptor in human skeletal muscle tissue. Histochem J. 2001;33(1):19-24.

60. Boland R. Role of vitamin D in skeletal muscle function. Endocr Rev. 1986;7(4):434-448.

61. Schubert L, Deluca HF. Hypophosphatemia is responsible for skeletal muscle weakness of vitamin D deficiency. Arch Biochem Biophys. 2010;500(2):157-161. 